\title{
Roberto Murillo y la superstición por la ciudad de Cartago
}

Jethro Masís*

https://orcid.org/0000-0001-9887-2269

Recibido: 22 de julio de 2020 • Aceptado: 18 de setiembre de 2020

\section{Resumen}

Roberto Murillo fue uno de los filósofos costarricenses más importantes del siglo XX. Aparte de su obra filosófica propiamente dicha, publicó una serie de artículos de prensa y ensayos breves en los cuales se explayó sobre la belleza de los paisajes costarricenses, su afición por las caminatas en el bosque y su alta estima por la ciudad de Cartago. Este artículo se ocupa precisamente de lo que él mismo llamó su superstición por la vieja metrópoli, que no solo tiene tintes anecdóticos, sino que exhibe - como se pretende mostrar- escorzos específicos de su pensamiento filosófico. En términos ulteriores, su veneración cartaginesa permitirá llevar a cabo una reflexión crítica más amplia sobre su estilo de pensamiento, enmarcado en los ideales humanistas de la primera generación de la comunidad filosófica costarricense.

Palabras clave: Filosofía costarricense, filosofía latinoamericana, tradición humanista.

* Doctor en Filosofía por la Universidad de Würzburg, Alemania. Profesor en la Escuela de Filosofía de la Universidad de Costa Rica, Costa Rica. Es presidente del Círculo Costarricense de Fenomenología y miembro de la comisión directiva del Círculo Latinoamericano de Fenomenología. Correo: jethro.masis@ucr.ac.cr 


\title{
Roberto Murillo and the superstition for the city of Cartago
}

\begin{abstract}
Roberto Murillo was one of the most remarkable Costa Rican philosophers of the 20th century. Aside from his philosophical work, Murillo authored a series of short pieces in which he elaborated on Costa Rican landscapes, his passion for hikes in the woods, and his high appreciation for the city of Cartago. This paper deals precisely with what Murillo himself called his superstition towards Cartago, although not only anecdotally but rather from the point of view of his philosophical thought. In the final analysis, Murillo's overt love for the city will allow a more ample critical reflection on his thinking, which was premised on the humanistic ideals entertained by the first generation of the philosophical community in Costa Rica.
\end{abstract}

Key words: Costa Rican philosophy, Latin America philosophy, humanistic tradition.

\section{Roberto Murillo et la vénération pour la ville de Cartago}

\section{Résumé}

Roberto Murillo a été l'un des philosophes costariciens les plus importants du XXème siècle. Parmi ses publications, notamment philosophiques, il a publié une série d'articles de presse et de courts essais dans lesquels il s'est exprimé largement sur la beauté des paysages costariciens, sur sa passion des randonnés dans la forêt et sa haute estime pour la cité de Cartago. Cet article concerne sur ce qu'il a nommé sa superstition pour la vielle métropole qui n'a pas seulement de traces anecdotiques sinon aussi-comme on veut le démonter-des vestiges de sa pensée philosophique. En d'autres termes, sa vénération pour Cartago permet de mener une réflexion critique approfondie de son style de pensée, encadré dans les idéaux humanistes de la première génération de la communauté philosophique costaricienne.

Mots-clés: Philosophie costaricienne, philosophie latinoaméricaine, tradition humaniste. 


\section{Introducción}

El filósofo costarricense Roberto Murillo (1939-1994), en varias ocasiones, confesó haber profesado «un culto pagano por el valle de Cartago» ${ }^{1}$ desde su adolescencia. Este estudio tiene como propósito dar cuenta de las razones que fundamentan esta veneración del filósofo por la vieja metrópoli y los vínculos más amplios de esta superstición con sus ideas sobre el derrotero histórico de la Universidad de Costa Rica y sobre el pensamiento filosófico en general.

Las piezas breves del filósofo costarricense forman parte de su obra filosófica y no solo constituyen una serie de devaneos pueriles o intentos poéticos sin rigor. Me parece que sería un error de bulto pensar que Murillo tiene por un lado una obra teórica y filosófica, al mismo tiempo que en ocasiones se dedicaba a escribir relatos interesantes sobre sus experiencias, viajes y caminatas. Precisamente por ello, Cartago nos ofrece la posibilidad de pensar una serie de temas y de problemas filosóficos más amplios. Sobre este método de interpretación, hago mías las palabras de Murillo, en la introducción a su libro sobre Antonio Machado: «he intentado seguir un método, un camino, que me parece no arbitrariamente impuesto al contenido de [su] filosofía» ${ }^{2}$.

\section{La ciudad mítica}

A pesar de su veneración por Cartago, Roberto Murillo nació en la ciudad de San José, razón por la cual no tenía más remedio que afirmar, en detrimento de su origen josefino, que era cartaginés por adopción y conversión. Sus estudios secundarios en el Colegio de San Luis Gonzaga merecen unas líneas aparte, pues todavía a mitad del siglo XX se trataba de un colegio cuyo nombre decía prestigio, tradición y leyenda. Cuando Murillo hizo sus estudios secundarios en la década de 1950, ya la época de los jesuitas parecía cosa de otro siglo, y la dirección de Alejandro Aguilar Machado distaba en sus maneras, según Murillo, de «la disciplina prusiana de la época de Lachner» ${ }^{3}$. Tal como ha dicho Constantino Láscaris, durante buena parte del siglo XIX, el Colegio de San Luis Gonzaga «fue el centro modelo del país» ${ }^{4}$.

Esta es la razón por la cual Murillo no se cansa de ufanarse de su abolengo gonzaguista: «lo normal es hacer los estudios en aquella institución, el liceo más antiguo del país, por vivir en Cartago. A mí me ocurrió lo contrario: mi familia se trasladó a Cartago para que yo estudiara en ese colegio, aún prestigioso» ${ }^{5}$.

Desconozco si existe algún estudio sobre Cartago, no como lugar geográfico real, sino como un ideal, como una categoría espiritual. La voluminosa Monografía de

\footnotetext{
${ }^{1}$ Roberto Murillo, Estancias del pensamiento (San José: Editorial Costa Rica, 1978), 16.

${ }^{2}$ Antonio Machado, Ensayo sobre su pensamiento filosófico (San José: Fernández Arce, 1975), 13.

${ }^{3}$ Roberto Murillo, Segundas estancias (Cartago: Editorial Cultural Cartaginesa, 1990), 153.

${ }^{4}$ Constatino Láscaris, Desarrollo de las ideas filosóficas en Costa Rica (San José: Editorial Costa Rica, 1964), 211.

${ }^{5}$ Roberto Murillo, Segundas..., 55.

ESPIGA' @(1)(@) Año 21, N. ${ }^{\circ} 41: 01-15$, enero - junio 2021 
Cartago (1930, reimpresa en 1999, con una tercera edición en 2008), ciertamente documenta lugares, personajes y acontecimientos importantes de la historia cartaginesa, mas no en el sentido que el filósofo costarricense le otorga a la ciudad brumosa $^{6}$. De hecho, Murillo sostiene que, a la ciudad de Cartago, uno puede convertirse, tal como si se tratase de profesar la fe de una nueva religión. Por ello, no huelga advertirle a la lectora y al lector josefinos - u oriundos de otros laresque la veneración por Cartago, ya sea de sus hijos naturales o adoptados, no encuentra parangón con ninguno de cualesquiera localismos que hacen parte de los usuales provincialismos nacionales. Se comprende de suyo el cariño por el propio terruño, pero Murillo profesa casi de forma fanática - como ya se ha apuntadoalgo que denomina superstición. Uno se lo imagina con una sonrisa en el rostro cada vez que repite en sus escritos dedicados a la vieja metrópoli la afirmación de Láscaris de que «Cartago es la ciudad verdaderamente seria de nuestro país» ${ }^{7}$.

Pero, antes de levantar sospechas, concedamos lo que se tiene por obviedad: Es cierto que Cartago es una ciudad conservadora, pacata y recatada, que su historia casi gravita enteramente en torno al culto a la Virgen de los Ángeles y a fiestas y tradiciones de carácter religioso; quienes albergan sentimientos hostiles hacia Cartago, no cejan de recordar que allí la gente se va a dormir a la hora en que lo hacen las gallinas, después del chocolate y cuando suenan las campanas de la iglesia ¿A qué viene entonces la pasión desaforada por un pueblo de raíces coloniales que persiguió al Bachiller Osejo a causa de sus ideas liberales y republicanas en medio de los altisonantes fueros de la independencia? ¿No es acaso San José, la nueva metrópoli, la ciudad que encarna el progresismo valeroso y el futuro del país? Es difícil borrar de la memoria los fueros imperialistas cartagineses que pretendieron la anexión indigna al imperio de Iturbide y la batalla de Ochomogo del 5 de abril de 1823; la decidida afición por Cartago suele provocar, las más de las veces, ceños fruncidos y actitudes de sospecha. Razones para el desdeño, como se ve, tampoco faltan.

Sin embargo, es el mito de la ciudad desaparecida al que se adhiere sin concesiones el filósofo costarricense. Por ello, ninguna antipatía es óbice para que Murillo sostenga una afirmación aventurada: «en pocos lugares destacan como allí vigorosas individualidades de pensamiento independiente, capaces como Mario Sancho de una lucha quijotesca y amante contra el propio terruño ${ }^{8}$. Para dar cuenta de esta independencia del pensamiento, sucede lo que Aristóteles argüía como prueba para la intelección adecuada de la prudencia; a saber, «considerando a quienes solemos llamar prudentes» ${ }^{9}$. De manera semejante, el pensamiento independiente cartaginés se comprueba en la misma existencia de vigorosas individualidades, como la de Mario Sancho. Con Sancho, Murillo comparte esa suerte de nostalgia por un tiempo originario que evoca con tristeza la mítica ciudad perdida para siempre después del terremoto de 1910. Es como si al citar las palabras de Sancho de 'La vuelta al viejo solar’ — «su página mejor lograda ${ }^{10}$ —, el filósofo costarricense las hiciese parte de un recuerdo nostálgico que también le perteneciera:

\footnotetext{
${ }^{6}$ Jesús Mata Gamboa, Monografía de Cartago (Cartago: Editorial Tecnológica, 2008).

${ }^{7}$ Roberto Murillo, Segundas..., 173.

${ }^{8}$ Ibíd., 174.

${ }^{9}$ Aristóteles, Ética nicomáquea. Ética Eudemia (Madrid: Gredos, 1998), VI, 5, 1140a.

${ }^{10}$ Roberto Murillo, Segundas..., 144. 
pero el alma verdadera de Cartago se ha ido para siempre, y yo que prácticamente no he vivido aquí después del terremoto, sino de paso, sin poder fijarme bastante para olvidar a la antigua ciudad tradicional que todavía llevo íntegra, sin la menor resquebrajadura, en mi memoria, me siento como huérfano de aquellas viejas torres, de aquellas casonas señoriales y de aquella antigua gente, que diría Leopardi, más seria, más fuerte, de costumbres más limpias y de gustos más sobrios ${ }^{11}$.

Mario Sancho es, a no dudarlo, uno de los casos más ejemplares de un intelectual costarricense transido de una adoración inamovible por su terruño cartaginés, que no cambia ni siquiera por las grandes ciudades en las que vivió por muchos años, como París y Boston. Quienes en vida admiraron a Mario Sancho lo adjetivan de «alto valor intelectual costarricense» ${ }^{12}$ o de «uno de los más ilustres representantes de la intelectualidad de Costa Rica» ${ }^{13}$. Bien se sabe que Abelardo Bonilla ha dicho que su estilo es «el mejor de la prosa costarricense» ${ }^{14}$. Lo de Murillo, sin embargo, tiene que ver con otra cosa: con la nostalgia. Pero no se trata simplemente de una actitud romántica hacia la desaparición de la ciudad de la que se dice hijo adoptivo, sino de un lamento por una forma de ser, por una cultura y una manera de existir que personalidades como Mario Sancho encarnaban a cabalidad. La tragedia de Cartago radica en el derrumbe de una arquitectura del espíritu, en la desaparición para siempre de individualidades independientes y vigorosas. A este respecto, Mata Gamboa cita las palabras de Antonio Zambrana: «un grupo de hombres honrados y trabajadores que miran la tierra sin miedo y al cielo sin rubor. ¿No significa eso Cartago?» ${ }^{15}$.

\section{La nostalgia}

Se explica de suyo, sin embargo, que la nostalgia no suele emplazarse en la lista de conceptos a los que se tiene en alto aprecio; pues la nostalgia es cosa más bien trillada, la manía de quienes alcanzan la madurez y se dejan embargar por un pesado sentimiento de pérdida, que evoca las maneras del tiempo pasado como mejores y más robustas, cual si fuesen tanto más serias respecto de ciertos valores que el presente ha abandonado y de los que ni siquiera tiene noticia. Murillo se expresa en muchas ocasiones de forma nostálgica acerca de tiempos, no tan lejanos, en que no se había roto - según su juicio- «todo nexo entre virtud y reconocimiento, creíamos en la honradez y en el trabajo, algo nos decía aún la palabra distinción» ${ }^{16}$.

Por la misma razón, el aristocratismo espiritual de Mario Sancho pervive intocado en los enjuiciamientos constantes con que Murillo se abalanza contra lo que se le antoja una forma fatal de nivelación que no admite distinciones, «una democracia

\footnotetext{
${ }^{11}$ Mario Sancho, «La vuelta al viejo solar». Repertorio Americano 25, n. ${ }^{\circ} 23$ (1932): 357.

${ }^{12}$ Vicente Sáenz, Ensayos escogidos (San José: Editorial Costa Rica, 1983), 79.

${ }^{13}$ Luis Vives, «Mario Sancho ha muerto». Repertorio Americano XLIV, n. ${ }^{\circ} 7$ (1948): 264.

${ }^{14}$ Abelardo Bonilla, Historia de la literatura costarricense (San José: Editorial Costa Rica, 1967), 415.

${ }^{15}$ Jesús Mata Gamboa, Monografía..., 666.

${ }^{16}$ Roberto Murillo, Segundas..., 154. 
mal entendida ${ }^{17}$. Ya en su tiempo tuvo que haberle caído mal a más de uno la crítica del filósofo costarricense de lo que llamó 'el despotismo necesario', que, por mor de la igualdad, elimina «toda cabeza que se levante sobre la mediocridad general» ${ }^{18}$.

Este despotismo tiene como propósito el cortar cabezas, para eliminar toda aristocracia intelectual: «habrá que vaciar los ojos de Homero, arrancar la lengua a Cicerón y lapidar a Shakespeare, así como sospechar incluso de las gentes demasiado bellas» ${ }^{19}$. Sin duda, Murillo coincidiría con Sloterdijk en que «quien busque hombres encontrará acróbatas» ${ }^{20}$. La idea de altura de Murillo también coincide con esa suerte de transvaloración nietzschena de todos los valores cara a Sloterdijk que hace posible

una definición no económica de la riqueza, una definición no aristocrática del noble, una definición no atlética de un rendimiento de primera clase, una definición no señorial de lo superior, una definición no ascética de la perfección, una definición no militar de la valentía, una definición no beata de la sabiduría y de la fidelidad ${ }^{21}$.

Murillo es nostálgico, incluso cuando habla de sus años mozos como estudiante en el Departamento de Filosofía, de las décadas de 1950 y 1960. Según sus recuerdos, sus maestros (Láscaris, Olarte y Bonilla) se batían a duelo encarnizado sin concesiones, pero compartían una afinidad por la libertad del pensamiento que ya en la década siguiente no constituía el estado natural de las cosas. El caso es que aquellos maestros, y en el ambiente intelectual, promovían «un hilo conductor que antes, de puro evidente, no destacábamos. Como hombres y como pensadores, los tres ponían la libertad por encima de todas las cosas $»^{22}$. Con la distancia temporal precisa, a Murillo se le hacía evidente que la desaparición de aquellos, sus maestros, venía acompañada del infortunio de la sustitución de una forma de vida universitaria, la más apta para el ejercicio del filosofar, por un ascenso de mezquindades y sectarismos insospechados en los mejores tiempos del Departamento de Filosofía.

Algo había cambiado - inadvertidamente - para mal. En cualquier caso, tal vez no sea casualidad el vínculo, ya sea directo o indirecto entre aquellos maestros venerados por el filósofo costarricense, con Cartago. Abelardo Bonilla, al igual que Murillo, cursó sus estudios secundarios en el Colegio de San Luis de Gonzaga, y Teodoro Olarte fue profesor en la misma institución en la década de 1940. Mientras tanto, Láscaris hacía el viaje desde San José a la ciudad que había denominado la más seria del país, para participar en las reuniones del Círculo de Cartago, si no es que hasta Turrialba, donde era miembro de una sociedad intelectual.

La comparación entre Roberto Murillo y Mario Sancho no es gratuita. Ambos tienen un talento brutal para poner sobre el papel su nostalgia y hacer desfilar ante los ojos de la imaginación una vida, unos personajes y unos lugares para siempre

${ }^{17}$ Ibíd.

${ }^{18}$ Roberto Murillo, Estancias..., 88.

${ }^{19}$ Ibíd.

${ }^{20}$ Sloterdijk, Has de cambiar tu vida. Sobre antropotécnica (Valencia: Pre-Textos, 2013), 29.

${ }^{21}$ Ibíd.

${ }^{22}$ Roberto Murillo, Segundas..., 109. 
desaparecidos. Leyendo las Memorias de Sancho ${ }^{23}$, casi puede uno verlo en las horas de zozobra que siguieron al terremoto de 1910, ingresando a la Basílica como un Indiana Jones, en medio de temblores amenazantes y el latente peligro de derrumbe de toda la estructura, con el único fin de rescatar a la Virgen de los Ángeles. Merced a su potencia narrativa, casi puede verse a la perfección la estampa de la desaparecida ciudad, con su aire señorial, sus calles empedradas y al poeta Rafael Angel Troyo paseando por las tardes en su caballo blanco importado del Perú. En lo tocante a la nostalgia filosofal de Murillo, viene a la mente la clara imagen de la fisga irónica de Láscaris, rechazando el sentimentalismo de Abelardo Bonilla, prendiendo un cigarrillo Ticos sin filtro para, por otra parte, confesarle a Olarte - sosteniendo al fondo su pipa - su propia desconfianza en ese su optimismo evolucionista caro a Teilhard de Chardin. Murillo contagia su nostalgia y su sentimiento triste de la pérdida del tiempo irrecuperable. Es como si fuera un prestidigitador de la memoria para siempre perdida. Lo de Sancho es una verdadera película de personajes vestidos de forma distinguida un día sábado para tomar café en el círculo literario de los Troyo y esperar a la noche el concierto musical en casa de las Espinach, donde doña Mercedes tocaría el piano para el aria que cantaría doña Teodorita. Como sostiene Sancho, Cartago «era una ciudad pequeña y modesta, pero con carácter propio, con un aire inconfundible de hidalguía que lograba infundir una sensación de buen tono y de noble sosiego» ${ }^{24}$. Lo de Murillo es el anhelo por una época de la filosofía institucional en la que no existía una actitud plagada del «peligrosísimo complejo de subdesarrollo que se apoderó en los setentas de muchos dirigentes universitarios» ${ }^{25}$.

También acá había mejor tono y un noble sosiego. Un aire inconfundible de hidalguía del pensamiento. ¿En qué habrá consistido aquel complejo de subdesarrollo? Según Murillo, en el ambiente en que él se formó,

se nos hizo creer que éramos dignos de una enseñanza y de una actitud en nada inferiores a las europeas, que con diligencia podíamos compensar las naturales limitaciones del país, que la lectura de las obras técnicamente difíciles de los grandes maestros, a menudo realizada en los textos en lengua original, no era imposible, que el doctorado era una cosa humana, no utópica ${ }^{26}$.

¿Qué habrá comenzado a cambiar en la década de $1970 ?$

\section{La ciudad y la universidad}

Avanzaré ahora una tesis todavía más atrevida: en las reflexiones del filósofo costarricense, Cartago y la Universidad de Costa Rica constituyen un espejo paralelo, de ahí su decidido interés en las reflexiones de Mario Sancho sobre Cartago. Uno se pregunta ¿A qué viene esa ciudad estéticamente sin distinción, de mal gusto, fea sin más, que fue levantada sobre los escombros de su mítica versión? El tema es insistente en Mario Sancho: lo nuevo no es solamente peor, sino

\footnotetext{
${ }^{23}$ Mario Sancho, Memorias (San José: Editorial Costa Rica, 1976).

${ }^{24}$ Mario Sancho, «Las casas solariegas del antiguo Cartago», Repertorio Americano 24, n. ${ }^{\circ}$

2 (1933): 32.

${ }^{25}$ Roberto Murillo, Segundas..., 104.

26 Ibíd.
} 
muchísimo peor. Aunque Murillo no establece directamente el solapamiento entre la ciudad y la universidad, la vieja metrópoli y la institución; sin embargo, se antojan espejos exactos que se reflejan como la pérdida de algo fenecido. El filósofo admira al potente ensayista cartaginés por su mirada comparativa entre algo viejo y las nuevas veleidades; empero, la nostalgia, sobre todo así de expresa y sin concesiones, suele provocar desconfianzas. Ahora bien, no se crea que Mario Sancho no lo sabe: «los más de mis lectores no se explican de seguro por qué he de pasarme la vida suspirando por el antiguo Cartago. Algunos de ellos considerarían esto una manía, y quizá la relacionen con cierto trasnochado romanticismo» ${ }^{27}$. Murillo tampoco ignora la admonición crítica que se abalanza contra «los espejismos jóvenes y románticos que nos hacen creernos el centro de la historia» ${ }^{28}$. Ni uno ni otro, ni el ensayista ni el filósofo se estiman a sí mismos como románticos ingenuos.

Mario Sancho y Roberto Murillo se antojan, en una medida exacta, Doppelgänger. Pero ¿Tiene algo de cierto la convicción romántica de que todo tiempo pasado fue mejor? ¿No estamos más bien ante el típico caso del viejo que recuerda mal y que es inmune a las veleidades de su era? En arreglo con Murillo,

no importa que tal Cartago esté más en nuestra imaginación que en la realidad, pues quizá la de Cartago consista, más que en embellecer sus ruinas, en engendrar hombres serios, en el buen sentido de la palabra, que dondequiera que vivan, realicen la obra creadora con la limpieza de su talento y la solidez de su carácter ${ }^{29}$.

Es tan solo una concepción vulgar del tiempo la que lo representa como una sucesión de ahoras y que nos arranca de un pasado irrecuperable, sin retorno. He aquí la concepción de Murillo de los éxtasis tempóreos de la existencia: las raíces de un mundo pasado están también cargadas de futuro. No se anhela el pasado para volver a atrás de forma mágica, sino que se lanza la mirada hacia adelante, si bien pisando fuerte sobre el suelo todavía viviente de la efectividad histórica.

\section{El paganismo}

Si de Cartago es la nostalgia, lo es también, y en igual medida, el paganismo. El sentido original de pagano no es otro que el que se concede, por lo general de forma despectiva y con cierto horror, a los individuos que no adoran a Dios, sino a pagus: el campo. Tal yerro teologal sería como el embuste, grave por herético, de confundir al creador con su creación, a la belleza de lo hecho con el hacedor, a lo engendrado con quien engendró. En suma, al ens creatum con el increatum. El desmedro es así evidente, puesto que no se siguen las precauciones estatuidas desde antaño por la doctrina de la analogia entis que advierte el no confundir lo que es, en sentido rebajado, con aquello que engendra ab aterno toda existencia y todo ser. Y las imágenes de los campos abiertos reclamados por el paganismo recrean en la mente solo ritos con gente desnuda, si no es que la aparición del mismo diablo y brujas que danzan en torno al fuego. Todo el mundo sabe que hay algo divino en el campo,

${ }^{27}$ Mario Sancho, «Las fontanas de Cartago», en Mario Sancho. El desencanto republicano (San José: Editorial Costa Rica, 1986), 165.

${ }^{28}$ Roberto Murillo, Segundas..., 92.

${ }^{29}$ Ibíd., 175.

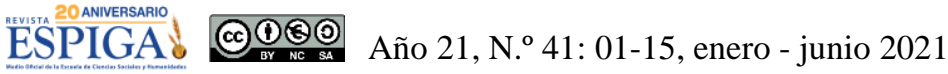


cuyos peligros teologales ya se ha encargado de advertir la sana y recta doctrina de la absoluta trascendencia. Por algo será. Pues bien, en numerosas ocasiones, Roberto Murillo se confiesa pagano en este sentido, a más que se carcajea a cada rato cuando recuerda que Constantino Láscaris, con su fisga casi cartaginesa, solía afirmar que los verdaderos paganos eran las personas oriundas de Cartago. Así las cosas, es cartaginesa de pura cepa la costumbre de ir a misa por la mañana y entregarse a pagus por las tardes: «en mi adolescencia me fui convirtiendo a ese peculiar paganismo, quizá de ancestro gallego, que Constantino Láscaris creía, en Costa Rica, exclusivo de Cartago: el amor al campo lleno de acequias, sauces y sementeras $»^{30}$.

Guardando las distancias y distinciones fundamentales que el caso demanda, lo que tiene nuestro filósofo de pagano deviene el motivo neurálgico para su talante casi lírico; de ahí el que se haya aventurado en el terreno de las prosas poéticas que «definen los lugares de mi vida modesta y extrañamente ennoblecida. Un Homero o un Sófocles me son tan entrañables como Kant y Platón, o, desde otro punto de vista, como el valle de Santa María ${ }^{31}$. Guido Fernández ha ensalzado apropiadamente lo que la prosa de Murillo tiene de seducción de lucidez: «sus artículos no son necesariamente evocaciones nostálgicas ni una incursión en el mundo de la poesía lírica. Roberto Murillo emplea el rigor de la descripción directa, sin los ornamentos de la imaginería, pero su diálogo con lo concreto no le impide alcanzar un idioma austeramente poético» ${ }^{32}$.

No cabe la menor duda de que en esto, Roberto Murillo, se revela como un romántico cabal. Recordado por sus discípulos, amigos y colegas como un hombre entregado a la filosofía, como pocos, la afición de Murillo por el diálogo mayéutico solo es comparable con su amor por las caminatas por las montañas y su fina observación de los paisajes costarricenses. Murillo fue un observador experto de la belleza, puntualmente de la belleza de parajes, bosques y cantones de Costa Rica. Sus artículos sobre Estrasburgo o sobre otras ciudades europeas (de Italia, Alemania y España, por ejemplo) evidencian su talento como descriptor paisajista. Su mirada, sobre todo, nunca dejó de constatar la belleza de su país, que retrató de forma magistral en más de una ocasión, y que sirvió como motivación para reflexiones filosóficas de gran calado.

La capacidad de observación, por cierto, no está dada de antemano ni es innata, sino que ciertamente puede extraviarse. Un filósofo debe aprender a observar. Como el ojo debe entrenarse para convertirse en un observador atento y concentrado; Murillo practicó el arte del caminar y del andar. Manuel Triana ha relatado que Murillo «conocía con lujo de detalles los lugares a dónde ir. Sabía dónde encontrar parajes hermosos, conocía muy bien las vías, los senderos, los atajos» ${ }^{33}$. Al mejor estilo heideggeriano, en Murillo los derroteros del pensar y los caminos de bosque constituían dos escorzos de su forma de vivir filosóficamente; y «muchos son los caminos que se dibujan y desdibujan sobre la tierra entrañable y divina ${ }^{34}$. Así, «caminos hay que se internan dentro del alma, por donde se va ocultando el pasado,

\footnotetext{
${ }^{30}$ Ibíd., 173.

${ }^{31}$ Roberto Murillo, Estancias..., 17.

${ }^{32}$ Ibíd., 8.

${ }^{33}$ Manuel Triana, «Roberto Murillo: maestro de vida universitaria», Revista de Filosofía de la Universidad de Costa Rica 42, n. ${ }^{\circ} 105$ (2004): 128.

${ }^{34}$ Roberto Murillo, Segundas..., 9. 
por donde se desvanecen imágenes queridas, allí donde se oye el alegre rumor de la juventud secreta, donde se juega el juego sin fin del tiempo con la permanencia» ${ }^{35}$.

No ignoro que la tentación inmediata sería definir a Murillo como un peripatético, pues tal cosa viene casi que exigida de suyo por las usuales imágenes que tenemos de la historia de la filosofía. Pero, se me antoja más apropiado caracterizarlo de pensador nómada, transido así de aquel espíritu arriesgado de descubrimiento y de la curiosidad, a veces deletérea, por lo que se encuentra más allá, que lanzó a la humanidad a habitar toda la tierra y a conquistar lo que, en principio, parecía imposible de alcanzar.

Habrá que hacer el estudio sobre los pensadores caminantes. Filosóficamente, en esto es Murillo un nietzscheano avant la lettre. De hecho, su 'Defensa del caminar' se abre con las palabras de Nietzsche: «la carne sedentaria es el auténtico pecado contra el espíritu santo» ${ }^{36}$. Con todo, más que contra el sedentarismo, su artículo se dirige polémicamente contra la moda de «correr, agitarse y sudar, de día y de noche, en la ciudad y en el campo ${ }^{37}$. Murillo se bate contra el encomio del correr, tan lleno de dioses y de héroes, que promete las glorias de la victoria e impulsa el espíritu competitivo. Los caminantes, dice Murillo, no tienen contrincantes, sino amigos con quienes conversar. El caminar, al contrario del correr, no se precipita hacia una meta prefijada, no se apura intensamente, sino que se demora en la paciencia. La fábula de la liebre y la tortuga — nos dice - es la prueba perfecta e irónica de que la ambición del corredor puede acabar en el ridículo: «sabio es el pueblo cuando dice que el que mucho corre, presto para ${ }^{38}$. La afición por el caminar y las dotes de Murillo para la observación de los paisajes constituyen caracteres fehacientes de una forma de filosofar que se obtiene ejercitando la mirada en el caminar, y que requiere, además, de la lentitud como su condición de posibilidad. Aprendemos de Murillo la relación intrínseca entre el caminar y el filosofar, y del caminar como metáfora de la existencia humana.

Nostalgia, observación de la belleza, cercanía entre la expresión poética y el pensamiento, son ideales que nos recuerdan la exigencia radical de Novalis de romantizar el mundo: die Welt muss romantiziert werden. Todo apunta a que el filósofo costarricense adhería a un ideal clásico de las ciencias humanas y a un ejercicio del filosofar cuyas perspectivas «pasan por lo claro, por lo oscuro, pero más frecuentemente por el claroscuro» ${ }^{39}$. No hay nada que nos haga concluir que Murillo se abanderaba bajo una concepción esotérica del pensamiento, pero su noción del claroscuro nos dice algo fundamental acerca de su idea del filosofar: como la dedicación disciplinada a las preguntas que no se pueden contestar en definitiva y que exigen de nuestra existencia una actitud vigilante y despierta de los límites de nuestra finitud.

${ }^{35}$ Ibíd., 10.

${ }^{36}$ Ibíd., 81.

${ }^{37}$ Ibíd., 83.

${ }^{38}$ Ibíd., 82.

${ }^{39}$ Ibíd., 32.

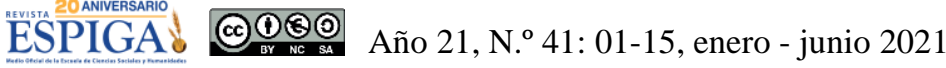




\section{Conclusiones}

La superstición por la ciudad de Cartago, a pesar de la inteligente y apasionada defensa montada por el filósofo costarricense, no se arranca de las acepciones nefandas que usualmente se asocian con cierta actitud romántica respecto de la tradición. No hay duda de que a las actitudes nostálgicas se adhieren usualmente concepciones ideológicas, incluso ridículas, tal como queda atestiguado en las palabras de Alberto Cañas: «Costa Rica era un oasis» ${ }^{40}$. Este supuesto oasis estaba, sin embargo, sumido en un círculo de violencia que, como han demostrado Manuel Solís ${ }^{41}$ y David Díaz ${ }^{42}$, hundía sus raíces en los conflictos anteriores que caracterizan la virulenta historia política costarricense.

Se ve por qué el romanticismo y la nostalgia del filósofo costarricense pueden fácilmente achacarse a su posición histórica y a la típica concepción exaltada de la época acerca de la excepcionalidad costarricense. Así las cosas, podríamos detectar sin problemas en las convicciones de Murillo una serie de vicios metafísicos que estudios críticos se han encargado de desenmascarar en las últimas décadas. Cabría preguntarse si Murillo puede incorporarse a la lista de filósofos de la primera mitad del siglo XX que Alexánder Jiméne ${ }^{43}$ motejó de nacionalistas étnico-metafísicos, dado que se deja entrever en las reflexiones del filósofo costarricense una expresa actitud nostálgica hacia los tiempos pasados. Como hemos podido corroborar, la nostalgia no solamente se refiere a la ciudad de Cartago, sino análogamente a la primera generación de la comunidad filosófica costarricense.

Las cuestiones críticas que hasta aquí se han ido acumulando merecen, seguramente, reflexiones más detalladas. No obstante, permítaseme motejar rápidamente al filósofo costarricense de humanista de vieja raigambre y, de ahí, sugerir una discusión que - a mí al menos - se me antoja fundamental. Desde hace décadas la tradición humanista provoca sospecha, si no es que la más abyecta falta de interés ¿No han sido paulatinamente desmontados los supuestos nucleares que antaño se asociaban con los ideales de la tradición del humanismo? Los ideales del humanismo se nos antojan hoy superados, refutados y añejos. Sus fines universales abstractos nos dicen muy poco en una época consagrada enteramente a la particularidad y al carácter situado de la experiencia humana, más aficionada a los estudios culturales y la crítica ideológica ¿No es más bien cuestión superada la de lanzar la mirada a los clásicos como si se tratase de un modelo perenne y eterno para lo que debemos pensar?

Las acepciones nefandas que, sin embargo, se asocian con el romanticismo, suelen más bien derivarse de una serie de prejuicios a los que no cabe referirse acá in extenso. Mi tesis es que el filósofo costarricense fue en esto también un nietzscheano cabal, puesto que compartía con el pensador alemán el concepto de allochronía, de

\footnotetext{
40 Alberto Cañas, Los 8 años (San José: Editorial de la Universidad Estatal a Distancia, 2014), 3 .

${ }^{41}$ Manuel Solís, La institucionalidad ajena. Los años cuarenta y el fin del siglo (San José: Editorial de la Universidad de Costa Rica, 2008).

${ }^{42}$ David Díaz, Crisis social y memoria en lucha: guerra civil en Costa Rica, 1940-1948 (San José: Editorial de la Universidad de Costa Rica, 2015).

${ }^{43}$ Alexánder Jiménez, El imposible país de los filósofos (San José: Editorial de la Universidad de Costa Rica, 2002).

ESPIGAd @(1)@(@) Año 21, N. ${ }^{\circ}$ 41: 01-15, enero - junio 2021
} 
intempestividad. Lo explica Sloterdijk: «la idea, tan sugestiva como fantástica, de que la Antigüedad no necesita ninguna repetición escenificada por obra de tiempos posteriores, ya que ella retorna constantemente, en el fondo, por sí misma, por su propio poder» ${ }^{44}$. Es la idea más radical de que la Antigüedad «está por encima de cualquier época... [por lo cual] podría ser llamada igualmente futuro, y lo que parece una vuelta atrás hacia ella es pensable también como un salto hacia adelante» ${ }^{45}$.

Según mi parecer, hay en todo esto un conflicto con la tradición humanista y con una serie de ideales que se nos antojan de difícil intelección en la actualidad. Si es cierto que Roberto Murillo fue un pensador transido de convicciones románticas y humanistas de viejo cuño, todo ello debe ser investigado de forma rigurosamente filosófica. Al acercarnos a los pensadores que formaron parte de la primera generación del Departamento de Filosofía, comprobamos que adherían a una serie de ideales filosóficos que hoy devienen extraños ¿Habremos de concluir que nuestra extrañeza se debe a que los hemos superado? ¿Están completamente enterrados para siempre los ideales de la tradición del humanismo? Si algo podemos aprender de la tradición humanista es el modelo hermenéutico dialógico, que concibe a la tradición como «un verdadero compañero de comunicación, al que estamos vinculados como lo está el yo al tú. Es claro que la experiencia del tú tiene que ser algo específico por el hecho de que el tú no es un objeto sino que él mismo se comporta respecto a uno» ${ }^{46}$. Por el contrario, quien nos sugiere que ha refutado para siempre mediante rigorismos lógico-formales el pensamiento de un filósofo del pasado, o que ha identificado los eufemismos del discurso y sus mecanismos culturales de fondo, nos está dando un botón de muestra en el mismo acto de una concepción errada de la crítica filosófica. La interpretación y la crítica serían así parte de un juego donde solamente juega una sola persona, emplazada desde una distancia y una altura omnisciente que la exime de ser interpelada por un tú.

Lo de hoy va más bien en colocar a la tradición humanista con sus textos, obras de arte y sus autores canónicos en el contexto más amplio de los mecanismos de dominación que le subyacen. La mirada crítica es, de esta forma, una estrategia de lectura que puede dirigirse a las obras clásicas de la tradición, pero solamente si deja ver a través de ellas algo que se esconde detrás: sus embustes ideológicos. No se trata más de encontrar belleza o inspiración en la poesía o en el arte, sino de sonsacar los elementos hegemónicos y violentos que subyacen en el fondo. Esta forma de ver puede caracterizarse como una mirada crítica que se erige ahora para quebrar lanzas y detectar culpables. En The Abolition of Man, C. S. Lewis caracteriza negativamente esta forma de ver porque no se puede siempre estar viendo a través de las cosas; está bien que la ventana sea transparente, porque así me permite ver el jardín, pero tal como pregunta C. S. Lewis ¿Qué pasaría si el jardín también fuera transparente y si pudiésemos ver a través de él? Respuesta: «si siempre vemos a través de todas las cosas, entonces todo es transparente. Pero un mundo enteramente transparente es un mundo invisible. Ver a través de todas las cosas es lo mismo que no ver nada ${ }^{47}$.

\footnotetext{
${ }^{44}$ Sloterdijk, Has de cambiar..., 50.

${ }^{45}$ Ibíd., 56.

${ }^{46}$ Hans-Georg Gadamer, Wahrheit und Methode. Grundzüge einer philosophischen Hermeneutik (Tübingen: J. C. B. Mohr, 1990), 364.

${ }^{47}$ Clive Staples Lewis, The Abolition of Man (New York: HarperCollins, 2015), 81. ESPIGA' @(1)(@) Año 21, N. ${ }^{\circ} 41: 01-15$, enero - junio 2021
} 
Los hondos problemas hermenéuticos relativos a la forma de enfrentarnos con la tradición deben discutirse más a fondo, pero este no es el lugar para hacerlo. Sin embargo, se puede concluir que el pensamiento de Roberto Murillo no está cancelado ni por asomo y que incluso su superstición por la ciudad de Cartago y su crítica correlativa del devenir de la institución filosófica merecen nuestra atención y consideración. A mi manera de ver, muy otra es la convicción que concibe lo pensado como repositorio muerto del pasado, que puede simplemente colocarse en el museo anticuado de la historia de las doctrinas superadas. Si, por el contrario, partimos de la convicción expresada por Heidegger en Platons Lehre von der Wahrheit, según la cual «la 'doctrina' de un pensador es lo no dicho en su decir... Para que podamos conocer y llegar a saber en el futuro lo no dicho por un pensador, sea ello del tipo que sea, tendremos que volver a pensar lo dicho por él ${ }^{48}{ }^{\prime}$, nos encontraremos en el mismo plano de interpretación y crítica que Murillo llegó a practicar en su obra. Por ello, no sabemos todavía lo que el pensamiento de Roberto Murillo da que pensar y las posibilidades abiertas de su filosofía para lo que todavía hemos de pensar si concebimos lo pensado como algo terminado y cerrado. Este mismo intento de visitar de nuevo el pensamiento del filósofo costarricense, no sería más que una suma de ejercicios inútiles y baladíes si su pensamiento careciese de efectividad para nuestro propio pensamiento y si lo diésemos por regazado o agotado. Estoy convencido de que Roberto Murillo nos saluda desde el futuro y que el ejemplo de su vida filosófica apunta en la dirección a lo que todavía hemos de pensar.

\section{Formato de citación según APA}

Masís, J. (2021). Roberto Murillo y la superstición por la ciudad de Cartago. Revista Espiga, 21 (41), páginas 01-15.

Formato de citación según Chicago-Deusto

Masís, Jethro. «Roberto Murillo y la superstición por la ciudad de Cartago». Revista Espiga 21, n. ${ }^{\circ} 41$ (enero-junio, 2021): páginas 01-15.

\section{Fuentes consultadas}

Aristóteles. Ética nicomáquea. Ética eudemia. Traducción de J. Pallí. Madrid: Gredos, 1998.

Bonilla, Abelardo. Historia de la literatura costarricense. San José: Editorial Costa Rica, 1967.

${ }^{48}$ Martin Heiddeger, Hitos (Madrid: Alianza, 2000), 173. 
Cañas, Alberto. Los 8 años. San José: Editorial de la Universidad Estatal a Distancia, 2014.

Díaz, David. Crisis social y memoria en lucha: guerra civil en Costa Rica, 19401948. San José: Editorial de la Universidad de Costa Rica, 2015.

Gadamer, Hans-Georg. Wahrheit und Methode. Grundzüge einer philosophischen Hermeneutik. Gesammelte Werke, Vol. 1. Tübingen: J. C. B. Mohr (Paul Siebeck), 1990.

Heidegger, Martin. Hitos. Traducido por H. Cortés y A Leyte. Madrid: Alianza, 2000.

Jiménez, Alexánder. El imposible país de los filósofos. San José: Editorial de la Universidad de Costa Rica, 2002.

Jiménez, Alexánder. «Constantino Láscaris, Costa Rica: nombres que se lleva el río». Semanario Universidad, 28 de marzo, 2012.

Láscaris, Constantino. Desarrollo de las ideas filosóficas en Costa Rica. San José: Editorial Costa Rica, 1964.

Lewis, Clive Staples. The Abolition of Man. New York: HaperCollins, 2015.

Mata Gamboa, Jesús. Monografía de Cartago. Cartago: Editorial Tecnológica de Costa Rica, 2008.

Murillo, Roberto. Antonio Machado. Ensayo sobre su pensamiento filosófico. San José: Fernández Arce, 1975.

Murillo, Roberto. Estancias del pensamiento. San José: Editorial Costa Rica, 1978.

Murillo, Roberto. Segundas estancias. Cartago: Editorial Cultural Cartaginesa, 1990.

Nietzsche, Friedrich. Así habló Zaratustra. Traducido por Andrés Sánchez Pascual. Madrid: Alianza, 1998.

Sáenz, Vicente. Ensayos escogidos. San José: Editorial Costa Rica, 1983.

Sancho, Mario. «La vuelta al viejo solar». Repertorio Americano 25, n. ${ }^{\circ} 23$ (1932): 357.

Sancho, Mario. «Las casas solariegas del antiguo Cartago». Repertorio Americano 24,.$^{\circ} 2$ (1933): 32 .

Sancho, Mario. Memorias. San José: Editorial Costa Rica, 1976.

Sancho, Mario. «Las fontanas de Cartago». En Mario Sancho. El desencanto republicano. Editado por Flora Ovares y Seidy Araya. San José: Editorial Costa Rica, 1986, 165-168.

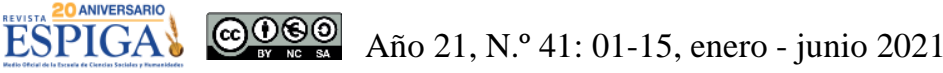


Sloterdijk, Peter. Has de cambiar tu vida. Sobre antropotécnica. Traducido por P. Madrigal. Valencia: Pre-Textos, 2013.

Solís, Manuel. La institucionalidad ajena. Los años cuarenta y el fin del siglo. San José: Editorial de la Universidad de Costa Rica, 2008.

Triana, Manuel. «Roberto Murillo: maestro de vida universitaria». Revista de Filosofía de la Universidad de Costa Rica 42, n. ${ }^{\circ} 105$ (2004): 127-130.

Vives, Luis. «Mario Sancho ha muerto». Repertorio Americano XLIV, n. ${ }^{\circ} 7$ (1948): 264. 